\title{
The serious full-length forearm injury - a case report and literature review
}

Jun Wang ${ }^{1,2}$ (D)

\begin{abstract}
Background: Among upper limb injuries, carpal bone fractures and dislocation, Essex-Lopresti injury, and the terrible triad injury of the elbow are serious and relatively rare injuries. These injuries require surgical intervention. The surgical method is difficult, and the treatment effect is poor. These injuries have not been described in the same limb in the literature.

Case presentation: A 21-year-old male patient fell from a height in our institution and sustained multiple injuries, including carpal bone fracture-dislocation, Essex-Lopresti injury, and the terrible triad injury of the elbow of his right upper limb. After 2 surgeries and rehabilitation, he returned to work. We reviewed available reviews and related literature on serious upper-limb damage.

Conclusions: Full-length forearm injury is very rarely encountered, and the management of such fractures is difficult. Radial head replacement with a metal prosthesis, reconstructed the IOM with Tightrope, and fixed the DRUJ with a K-wire pin is appropriate treatment.
\end{abstract}

Keywords: Dislocations, Elbow joint, Wrist injuries

\section{Background}

Among upper limb injuries, carpal bone fracturedislocation is relatively rare, and perilunate dislocations and fracture-dislocations account for approximately $10 \%$ of wrist injuries [1].Lunate subluxation, magnum bone, and scaphoid bone fracture are difficult to diagnose. A missed diagnosis can lead to wrist pain, and most of these injuries require open reduction and internal fixation [2]. The Essex-Lopresti injury is rare and caused by a high energy load, and the pattern of the injury consists of a fracture of the radial head ( $\mathrm{RH})$, account for $1 \%$ radial head fracture. Disruption of distal radioulnar joint (DRUJ) and rupture of the interosseous membrane. Repair of these injuries is technically demanding for surgeons [3]. The terrible triad of the elbow is one of the

\footnotetext{
Correspondence: junee@126.com

'Department of orthopedic, Xiaoshan 1st People's Hospital, Hangzhou 311200, China

2Department of orthopedic, Xiaoshan 1st People's Hospital, No. 199 Shixin Road, Hangzhou 311201, Zhejiang Province, China
}

most challenging injuries due to its complex injury pattern and compromised clinical results. This high-energy injury of the elbow joint consists of a characteristic triad, namely, posterior dislocation of the elbow associated with a radial head fracture and a coronoid fracture [4]. These injuries share the following characteristics: 1 . high-energy injury; 2. low incidence; and 3. extreme difficulty to treat. These damages occurred in the same limb, and such a case has not been described in the literature.

\section{Case presentation}

In November 2017, a 21-year-old man fell $7 \mathrm{~m}$ from an operation frame and injured his right upper extremity, lumbar spine, and pelvis. He presented to our institution $2 \mathrm{~h}$ after the injury. Physical examination revealed highgrade swelling, pain, deformities and limitation of function of the wrist and elbow as well as pain and limitation of function of the lumbar spine and pelvis. Radiographs of the wrist, elbow, lumbar spine, and pelvis revealed fractures of the magnum bone, scaphoid bone, the radial

(c) The Author(s). 2020 Open Access This article is licensed under a Creative Commons Attribution 4.0 International License, which permits use, sharing, adaptation, distribution and reproduction in any medium or format, as long as you give appropriate credit to the original author(s) and the source, provide a link to the Creative Commons licence, and indicate if changes were made. The images or other third party material in this article are included in the article's Creative Commons licence, unless indicated otherwise in a credit line to the material. If material is not included in the article's Creative Commons licence and your intended use is not permitted by statutory regulation or exceeds the permitted use, you will need to obtain permission directly from the copyright holder. To view a copy of this licence, visit http://creativecommons.org/licenses/by/4.0/ The Creative Commons Public Domain Dedication waiver (http://creativecommons.org/publicdomain/zero/1.0/) applies to the data made available in this article, unless otherwise stated in a credit line to the data. 


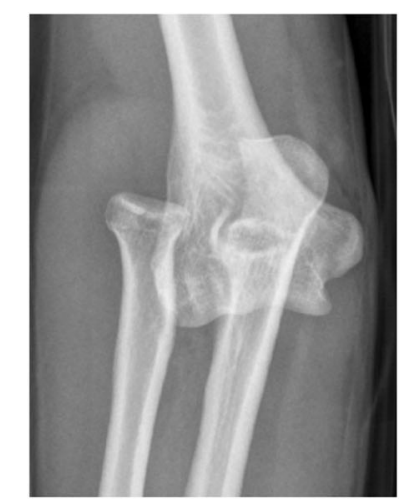

A

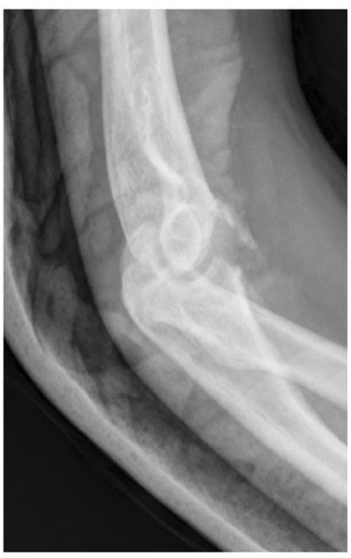

C

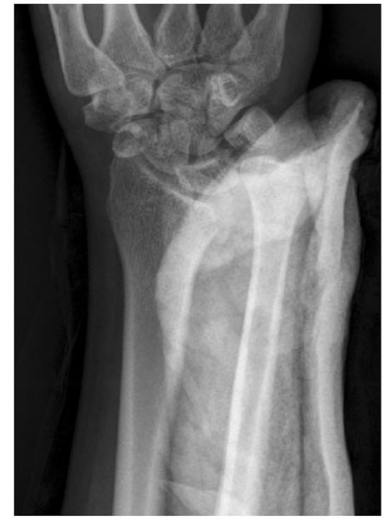

E

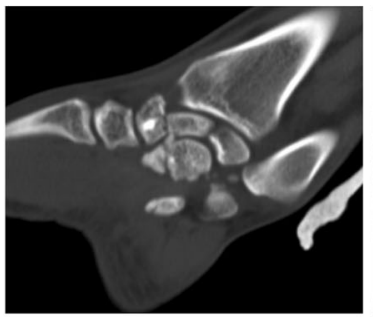

G

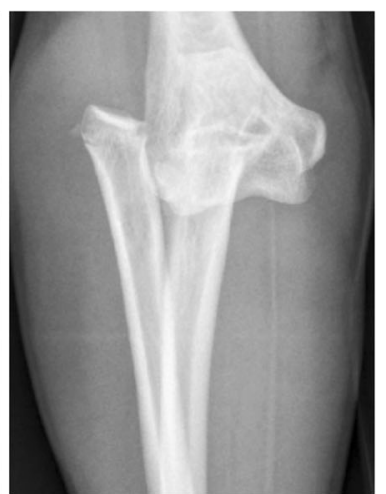

B

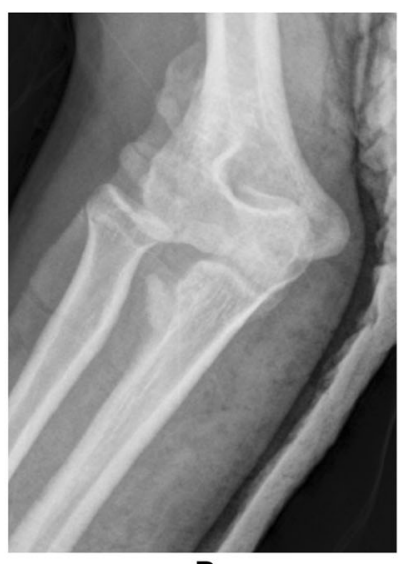

D

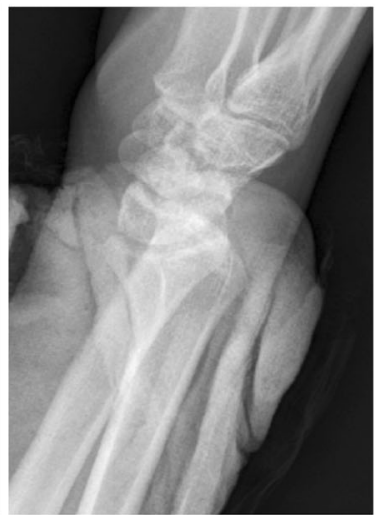

$\mathrm{F}$

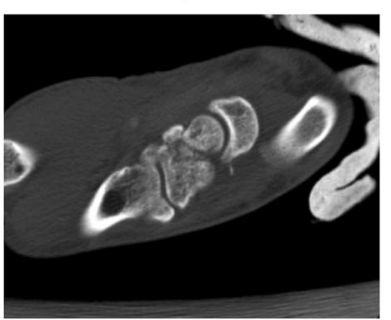

$\mathrm{H}$
Fig. 1 First radiographs, a anteroposterior view, $\mathbf{b}$ oblique view; c-d elbow joint after reduction; e-f wrist joint; $\mathbf{g}$-h wrist joint $\mathrm{CT}$

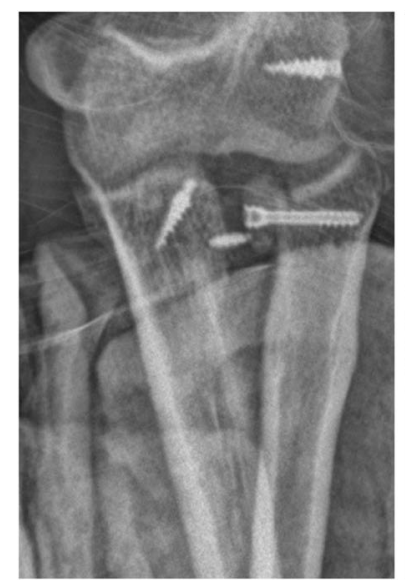

A

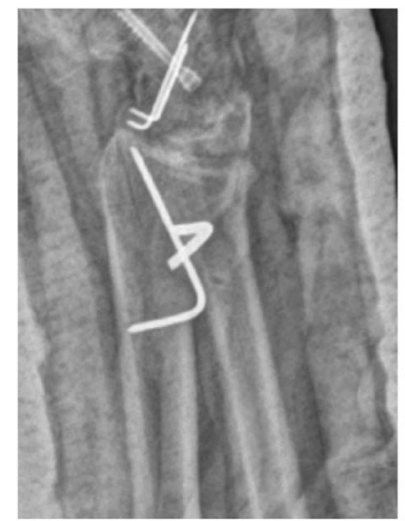

C

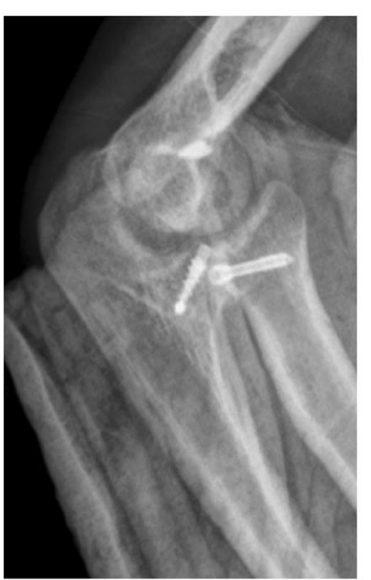

B

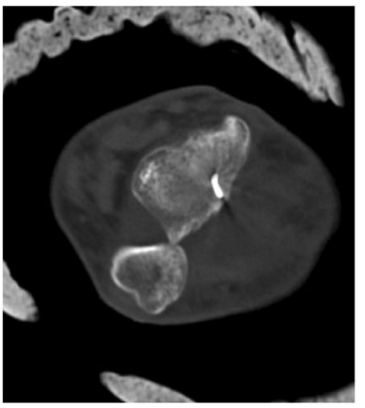

D
Fig. 2 After first surgery radiographs. a-b, elbow joint; c, wrist joint; d, $C T$ : wrist joint

head, the coronoid, the first lumbar vertebrae, and pelvis. Moreover, dislocation of the distal radioulnar joint, elbow, and lunate subluxation were noted. The diagnosis included carpal bone fracture-dislocation, Essex-Lopresti injury, terrible triad of the elbow (Fig. 1), lumber fracture, and pelvic fracture. He received analgesia for reduction of the elbow dislocation in the emergency room. Seven days later, surgical treatment was performed. Under general anesthesia, we performed the following techniques: open reduction and internal fixation with a $\mathrm{k}$-wire and Hebert screw via a dorsal incision to treat the carpal bone fracture-dislocation; open reduction and internal fixation with a Herbert screw to fix the radial head; suture anchor to fix the ulna coracoid process and radial collateral ligaments of elbow joint to treat the Essex-Lopresti injury and the terrible triad of elbow through an anterolateral approach of the elbow; and Kwire fixation to fix the distal radioulnar joint via a dorsal incision of the wrist (Fig. 2). X-rays show the malposition of the distal radioulnar joint 1 week after the 


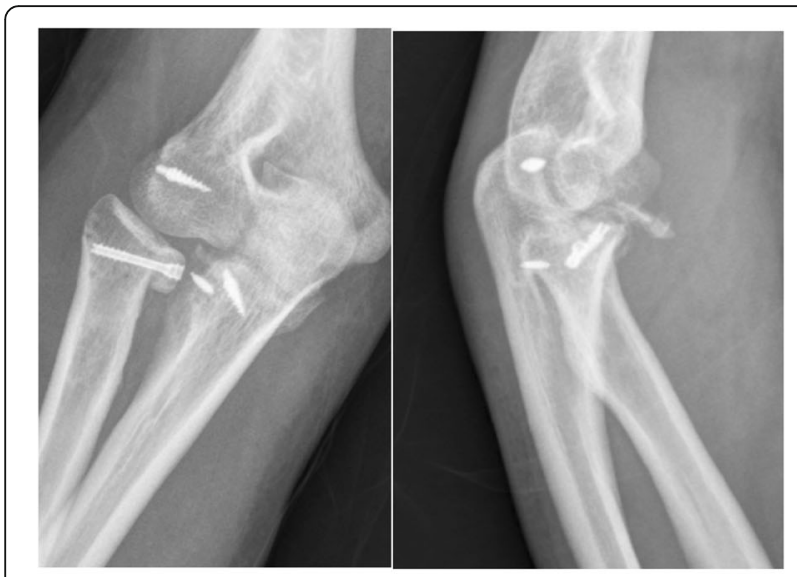

A

B

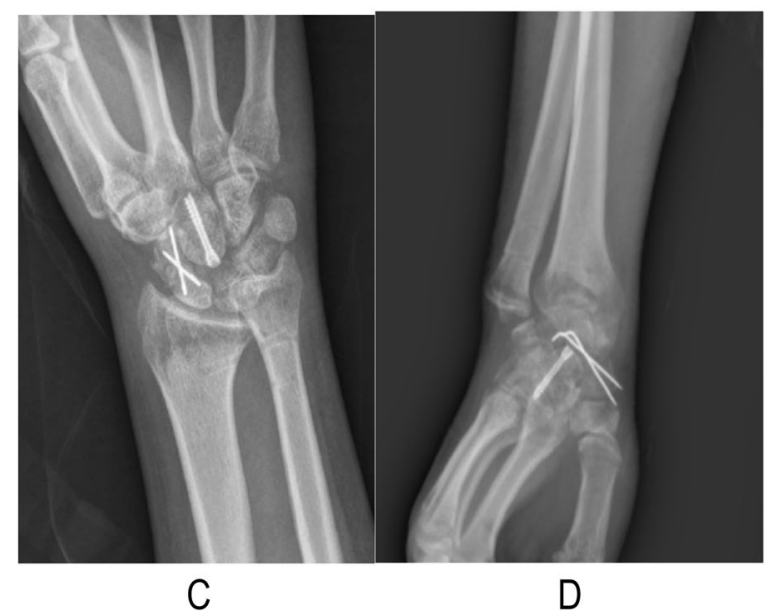

Fig. 3 Two months after first surgery radiographs. a-b, elbow joint; c-d,wrist joint

surgery. We removed the K-wire. Two months later, the patient felt pain in his wrist. We found that the malposition of the distal radioulnar joint was unchanged (Fig. 3). After a discussion with his parents, revision surgery was performed. The radial head was replaced with a metal prosthesis, and the distal ulna was removed. (Fig. 4).

After 12 months, the patient regained elbow flexion and extension strength (range of motion, $10^{\circ}-130^{\circ}$ ). His wrist was stable with subluxation of the distal radioulnar joint. The following forearm motion range was observed: supination, $0^{\circ}-70^{\circ}$; and pronation, $0^{\circ}-60^{\circ}$. The patient had returned to work. Three years later, we had checked the elbow joint and forearm function.(Fig. 5).

\section{Discussion and conclusions}

The terrible triad of the elbow and the Essex-Lopresti injury are severe and extremely rare upper-limb injuries $[5,6]$. We believe it is necessary to analyze the biomechanical relationship between the terrible triad of the elbow and the Essex-Lopresti injury. The injury mechanism for these injuries involves a violent axial

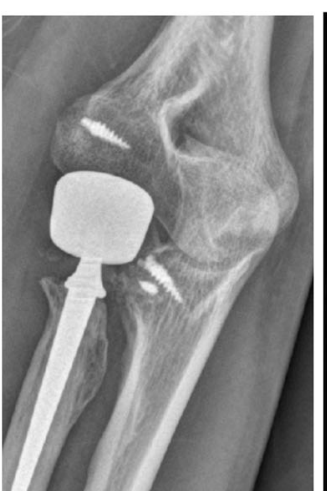

A

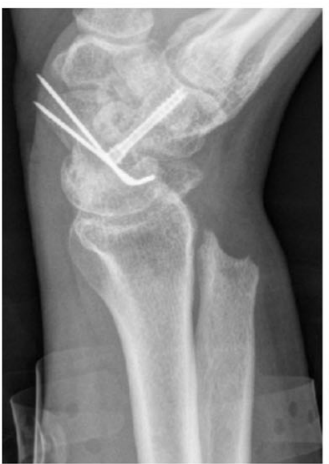

C

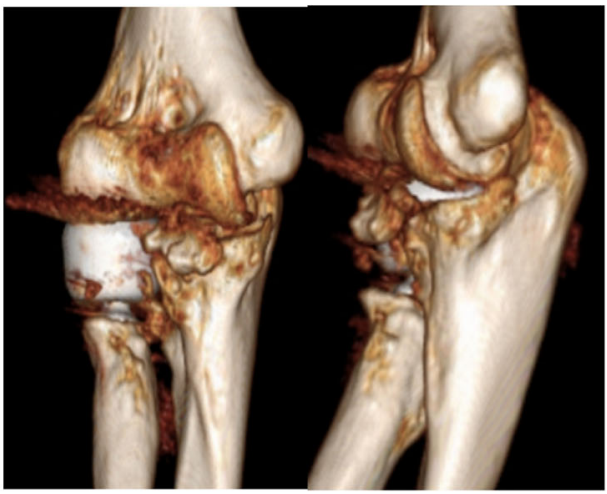

E

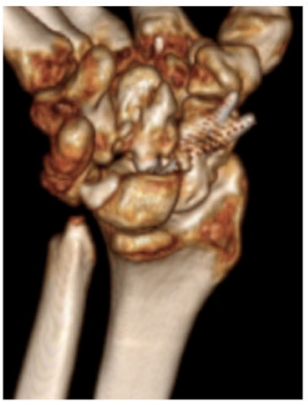

G

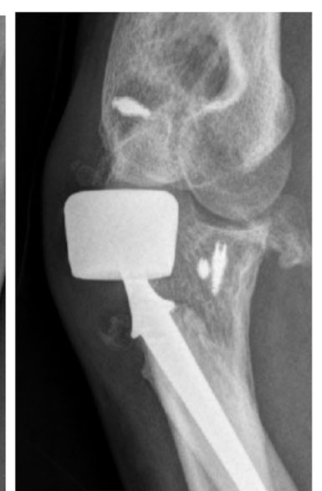

B

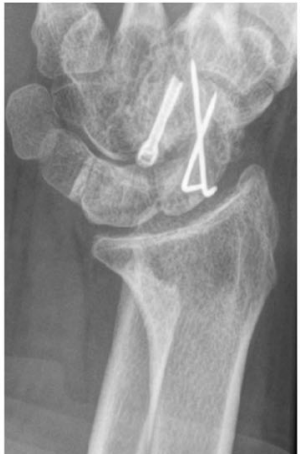

D

F

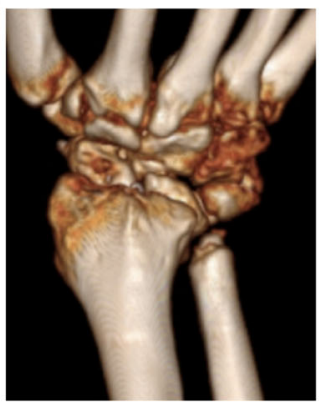

$\mathrm{H}$
Fig. 4 One year after second surgery radiographs. $\mathbf{a}-\mathbf{b}$, elbow joint; c-d, Wrist joint; e-f, CT: elbow joint; $\mathbf{g - h}$, CT: wrist joint 


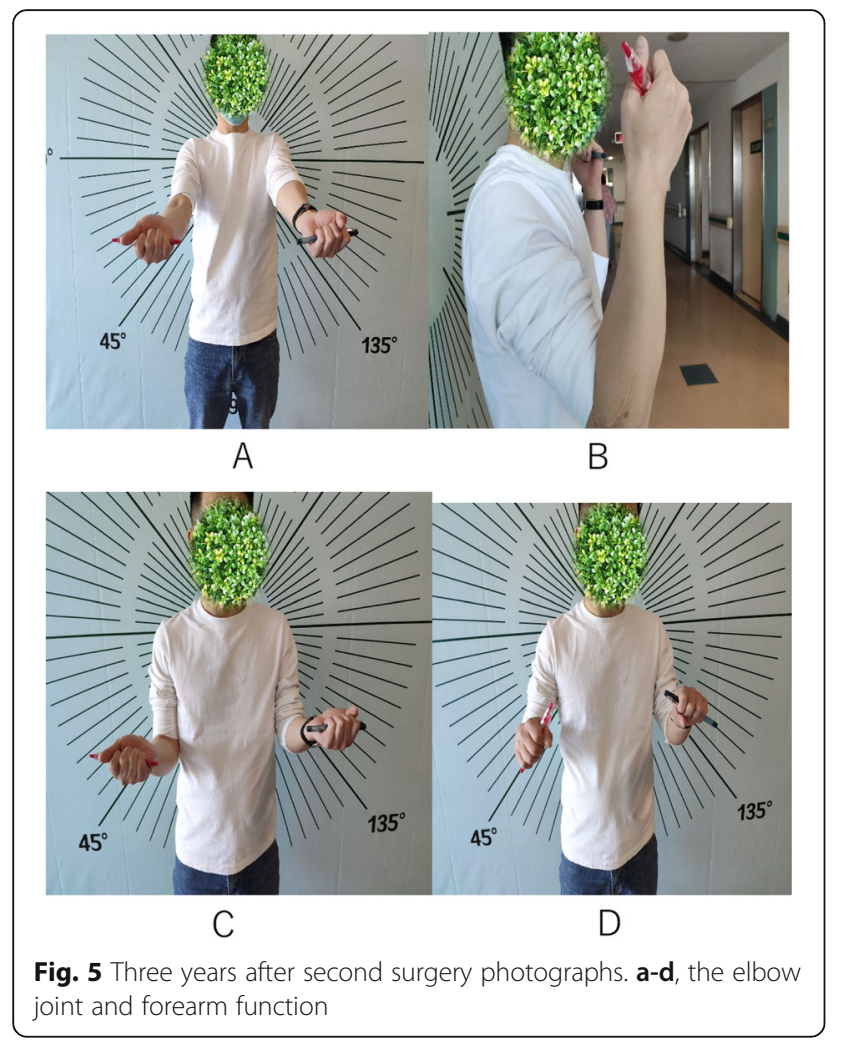

injury from the hand to the elbow with pronation or supination of the forearm. The terrible triad injury typically occurs when an axial load is applied to the arm. In addition, the elbow sustains a valgus load, and the forearm sustains supination. Eventual posterior elbow dislocation is associated an impaction fracture of the radial head and shear fracture of the coronoid process [7, 8]. The Essex-Lopresti injury typically results when an axial load is applied to the arm. The radiocapitellar joint has the most contact when the forearm in pronation. The entire load is transmitted through the radius to the radial head, causing migration of the radius and tearing of the interosseous membrane (IOM) [9].

In addition, the position of the forearm in space determines where the majority of the load is located. In pronation, the strain is mainly found in the proximal region, whereas the strain is increased distally in supination. The strain in the central band is significantly increased after excision as the forearm proceeds from a position of supination to pronation [9].

It is important to recognize that the position of the stretched arm at the time of injury will determine the injury pattern. This information is not commonly described in the literature because the forearm cannot undergo pronation and supination simultaneously. If the force is great enough, the forearm can proceed from a position of supination to pronation [10].
Terrible triad injuries are treated via a standardized surgical procedure that involves fixation or replacement of the radial head, coronoid fracture fixation, repair of the lateral collateral ligament, and if necessary repair of the medial collateral ligament. We used this procedure and obtained a satisfactory surgical outcome [11-13].

The treatment of the Essex-Lopresti injury remains controversial. The treatment has three areas of focus: 1 . Treatment of the radial head: In the acute phase, the native radial head should be preserved. The most favorable option involves anatomical reconstruction of the radial head with a Herbert screw or plate. If anatomical reconstruction is not possible, replacement should be performed [14]. In the chronic phase, the patient experiences pain and loss of strength at the elbow and/or wrist joint. The radial head of the elbow must be reestablished with a prosthesis $[15,16]$. Allograft, metal and silicone implants are available, and the desired clinical outcome is to recover the length of the limbs [17]. Mayhall et al. [18] reported that silicone implants are not suitable in this procedure. Radial head replacement with metallic implants appears to exhibit better outcomes [17].

2. Treatment of the interosseous membrane (IOM): The IOM plays an important role in forearm stability. However, IOM reconstruction in the acute phase is controversial [19]. Only a limited number of clinical studies on IOM reconstruction in patients have been reported. Brin et al. [20] described a case report of acute repair of the IOM using the TightRope device. IOM reconstruction techniques used during the chronic phase have been developed in recent decades. The ideal technique should involve anatomical reconstruction, and many reconstructive options have been reported in the literature $[10,21]$. Currently, two surgical methods are available: autogenous or allograft tendon (i.e., pronator teres tendon [22], bone-patellar tendon [23], and flexor carpi radialis autograft [24]) and various synthetic devices (suture-button [25] and Tightrope [26]). Complications include donor site pain and adverse impacts on forearm rotation [27]. Regardless of the method used to reconstruct the interosseous membrane, the original forearm stability cannot be obtained. Most of the above studies were performed on cadaver specimens, so clinical studies should be performed in the future.

3. Treatment of the distal radioulnar joint (DRUJ): In the acute phase, if good stability is observed, the forearm should be fixed for 6 weeks [28]. If the stability is poor, Kirschner wire or screws can be used to fix the ulnar radioulnar joint. TFCC can be simultaneously repaired to increase the stability of the lower radioulnar joint. In the chronic phase, many authors described treatment via ulnar shortening osteotomy [29]. The treatments for ulnar shortening osteotomy include distal ulna resection and shorten osteotomy 
of ulnar shaft with Locking Compression Plate (LCP) fixation [30].

In summary, full-length forearm injuries (carpal bone fracture-dislocation, Essex-Lopresti injury, and the terrible triad injury of the elbow) are very rarely encountered, and the management of such injuries can be technically demanding. We should be aware of the principles of the components of the severe injury. In the first surgery for this case, we should have performed radial head replacement with a metal prosthesis, reconstructed the IOM with Tightrope, and fixed the DRUJ with a Kwire pin given the significant force of these injuries. However, we lacked therapeutic experience when the case was first presented. In the second surgery for this case, we adhered to the treatment principles of a chronic Essex-Lopresti injury.

\section{Abbreviations}

IOM: Interosseous membrane; DRUJ: Distal radioulnar joint; RH: Radial head

\section{Acknowledgments}

Thanks are due to Dr. Minbo Liu for his precious help in revising this paper.

\section{Author's contributions}

The author(s) read and approved the final manuscript.

\section{Funding}

No funding was obtained for this study.

\section{Availability of data and materials}

This is a case report of a single patient, to protect privacy and respect confidentiality; none of the raw data has been made available in any public repository. The original reports, imaging studies and outpatient clinic records are retained as per normal procedure within the medical records of our institution.

\section{Ethics approval and consent to participate}

approved by ethics committee of xiaoshan 1st people's hospital.

\section{Consent for publication}

Since the patient was already deceased when this case report was written,patient's next of kin signed a written consent from indicating that he is aware of this case report and the possibility of it being published.

\section{Competing interests}

The authors declare that they have no competing interests.

Received: 18 February 2020 Accepted: 2 June 2020

Published online: 15 June 2020

\section{References}

1. Apergis E, Maris J, Theodoratos G, et al. Perilunate dislocations and fracturedislocations. Hand Clin. 2015;31(3):399-408.

2. Jones DB, Kakar S. Perilunate dislocations and fracture dislocations []]. J Hand Surg. 2012;37(10):2168-73.

3. Essex-Lopresti P. Fractures of the radial head with radio-ulnar dislocation: report of two cases. J Bone Joint Surg Br. 1951;33-B:244-7.

4. Hotchkiss RN. Fractures and dislocations of the elbow. In: Rockwood CA Jr, Green DP, Bucholz RW, Heckman JD. Rockwood and green's fractures in adults. 4th. Philadelphia: Lippincott-Raven; 1996. p 929-1024.

5. Falcon-Chevere JL, Mathew D, Cabanas JG, et al. Management and treatment of elbow and forearm injuries []]. Emerg Med Clin North Am. 2010;28(4):765-87.

6. Goldflam K. Evaluation and treatment of the elbow and forearm injuries in the emergency department. Emerg Med Clin North Am. 2015;33(2):409-21.
7. Beingessner DM, Pollock JW, King GJW. Elbow fractures and dislocations. In: Court-Brown CM, Heckman JD, McQueen MM, et al., editors. Rockwood and Green's fractures in adults. 8th ed. Philadelphia: Lippincott Williams \& Wilkins/Wolters Kluwer Health; 2015. p. 1180-227.

8. Dodds SD, Fishler T. Terrible triad of the elbow. Orthop Clin N Am. 2013; 44(1):47-58.

9. McGinley JC, Hopgood BC, Gaughan JP, Sadeghipour K, Kozin SH. Forearm and elbow injury: the influence of rotational position. J Bone Joint Surg Am. 2003;85-A(12):2403-9.

10. Skahen JR 3rd, Palmer AK, Werner FW, Fortino MD. Reconstruction of the interosseous membrane of the forearm in cadavers. J Hand Surg Am. 1997; 22(6):986-94.

11. Rodriguez-Martin J, Pretell-Mazzini J, Andres-Esteban EM, et al. Outcomes after terrible triads of the elbow treated with the current surgical protocols. A review [J]. Int Orthop. 2010;35(6):851-60.

12. Zhang C, Zhong B, Luo C-f. Treatment strategy of terrible triad of the elbow: experience in Shanghai 6th People's hospital [J]. Injury. 2014;45(6): 942-8.

13. Hong-Wei C, Guo-Dong L, Li-Jun W, et al. Complications of Treating Terrible Triad Injury of the Elbow: A Systematic Review. PLoS ONE. 2014;9(5):e97476.

14. Fowler JR, Goitz RJ. Radial head fractures: indications and outcomes for radial head arthroplasty. Orthop Clin North Am. 2013:44(3):425.

15. Venouziou Al, Papatheodorou LK, Weiser RW, Sotereanos DG. Chronic EssexLopresti injuries: an alternative treatment method. J Shoulder Elb Surg. 2014;23(6):861-6.

16. Duckworth AD, Wickramasinghe NR, Clement ND, et al. Radial Head Replacement for Acute Complex Fractures: What Are the Rate and Risks Factors for Revision or Removal? Clin Orthop Related Res. 2014;472(7):2136-43.

17. Heijink A, Morrey BF, van Riet RP, et al. Delayed treatment of elbow pain and dysfunction following Essex-Lopresti injury with metallic radial head replacement: a case series. J Shoulder Elb Surg. 2010;19(6):929-36.

18. Mayhall WS, Tiley FT, Paluska DJ. Fracture of silastic radial-head prosthesis. Case report. J Bone Joint Surg Am. 1981;63(3):459.

19. Hotchkiss RN, An KN, Sowa DT, et al. An anatomic and mechanical study of the interosseous membrane of the forearm: Pathomechanics of proximal migration of the radius. J Hand Surg. 1989;14(2):256-61.

20. Brin YS, Palmanovich E, Bivas A, et al. Treating acute EssexLopresti injury with the TightRope device: a case study. Tech Hand Up Extrem Surg. 2014; 18(1):51-5.

21. Marcotte AL, Osterman AL. Longitudinal Radioulnar dissociation: identification and treatment of acute and chronic injuries [J]. Hand Clin. 2007;23(2):195-208.

22. Chloros G D , Wiesler E R, Stabile K J, et al. Reconstruction of Essex-Lopresti injury of the forearm: technical note [J]. J Hand Surg, 2008, 33(1):0-130.

23. MAGUBANE. Structural properties of reconstruction constructs for the interosseous ligament of the forearm. J Hand Surg. 2005:30(2):312-8.

24. Matthias R, Wright TW. Interosseous membrane of the forearm. J Wrist Surg 2016:5(3):188-93.

25. $\mathrm{Cg} \mathrm{M}, \mathrm{Cl} \mathrm{F}, \mathrm{Ka}$ S. Suture-button reconstruction of the interosseous membrane. J Wrist Surg. 2016;5:179-83. https://doi.org/10.1055/s-00361584547.

26. Hackl M, Andermahr J, Staat M, et al. Suture button reconstruction of the central band of the interosseous membrane in Essex-Lopresti lesions: a comparative biomechanical investigation. J Hand Surg Eur Vol. 2016;42(4):370-6.

27. Miller AJ, Naik TU, Seigerman DA, et al. Anatomic Interosseus membrane reconstruction utilizing the biceps button and screw Tenodesis for EssexLopresti injuries. Tech Hand Upper Extrem Surg. 2015;20(1):1.

28. Ruszynski AM, Orellana-Rios CL, Becker G. Management of the Essex-Loprest Injury [J]. J Wrist Surg. 2016;05(03):172-8.

29. Marcotte AL, Osterman AL. Longitudinal radioulnar dissociation: identification and treatment of acute and chronic injuries. Hand Clin. 2007; 23(2):195-208.

30. lacobellis C, Biz C. Plating in diaphyseal fractures of the forearm. Acta Biomed. 2014:84(3):202-11 Published 2014 Jan 23.

\section{Publisher's Note}

Springer Nature remains neutral with regard to jurisdictional claims in published maps and institutional affiliations. 